\title{
Correlation between Coulomb stress changes imparted by large historical strike-slip earthquakes and current seismicity in Japan
}

\author{
Takeo Ishibe $^{1}$, Kunihiko Shimazaki ${ }^{1,2}$, Hiroshi Tsuruoka ${ }^{1}$, Yoshiko Yamanaka ${ }^{3}$, and Kenji Satake ${ }^{1}$ \\ ${ }^{1}$ Earthquake Research Institute, the University of Tokyo, 1-1-1 Yayoi, Bunkyo, Tokyo 113-0032, Japan \\ ${ }^{2}$ Association for Earthquake Disaster Prevention, 5-26-20 Shiba, Minato, Tokyo 108-0014, Japan \\ ${ }^{3}$ Research Center for Seismology, Volcanology and Disaster Mitigation, Graduate School of Environmental Studies, \\ Nagoya University, Furo-cho, Chikusa-ku, Nagoya 464-8601, Japan \\ (Received June 25, 2010; Revised January 26, 2011; Accepted January 27, 2011; Online published March 4, 2011)
}

\begin{abstract}
To determine whether current seismicity continues to be affected by large historical earthquakes, we investigated the correlation between current seismicity in Japan and the static stress changes in the Coulomb Failure Function $(\triangle \mathrm{CFF})$ due to eight large historical earthquakes (since 1923, magnitude $\geq 6.5$ ) with a strike-slip mechanism. The $\triangle \mathrm{CFF}$ was calculated for two types of receiver faults: the mainshock and the focal mechanisms of recent moderate earthquakes. We found that recent seismicity for the mainshock receiver faults is concentrated in the positive $\triangle$ CFF regions of four earthquakes (the 1927 Tango, 1943 Tottori, 1948 Fukui, and 2000 Tottori-Ken Seibu earthquakes), while no such correlations are recognizable for the other four earthquakes (the 1931 NishiSaitama, 1963 Wakasa Bay, 1969 Gifu-Ken Chubu, and 1984 Nagano-Ken Seibu earthquakes). The probability distribution of the $\triangle \mathrm{CFF}$ calculated for the recent focal mechanisms clearly indicates that recent earthquakes concentrate in positive $\triangle \mathrm{CFF}$ regions, suggesting that the current seismicity may be affected by a number of large historical earthquakes. The proposed correlation between the $\triangle \mathrm{CFF}$ and recent seismicity may be affected by multiple factors controlling aftershock activity or decay time.
\end{abstract}

Key words: Background seismicity rate, static change in the Coulomb Failure Function $(\Delta \mathrm{CFF})$, recent seismicity, large historical earthquakes.

\section{Introduction}

Many studies have focused on earthquake triggering and seismicity rate changes due to changes in the Coulomb Failure Function $(\triangle \mathrm{CFF})$ resulting from large earthquakes (e.g., Harris and Simpson, 1992, 1996; Reasenberg and Simpson, 1992; Stein et al., 1992, 1994; Simpson and Reasenberg, 1994; Harris et al., 1995; Hashimoto, 1995, 1997; Toda et al., 1998; Stein, 1999; Ma et al., 2005; Steacy et al., 2005; Ogata, 2006, 2007; Toda and Matsumura, 2006; Ogata and Toda, 2010). The $\Delta \mathrm{CFF}$ is defined as

$$
\Delta \mathrm{CFF}=\Delta \tau-\mu^{\prime} \Delta \sigma
$$

where $\Delta \tau$ is the shear stress change resolved on a given failure plane (assumed to have a positive value in the fault slip direction); $\Delta \sigma$ is the normal stress change (assumed to have a positive value in the compressive direction); $\mu^{\prime}$ is the effective coefficient of friction, defined by $\mu^{\prime}=\mu(1-B)$. Here, $B$ is the Skempton's coefficient, varying between 0 and 1 , and $\mu$ is the coefficient of friction. Positive values of $\triangle \mathrm{CFF}$ promote failures; negative values suppress failures. Two types of receiver faults have been assumed in discussions on the spatial correlation between the $\triangle \mathrm{CFF}$ due to large earthquakes and the subsequent aftershock distribution: a specified receiver fault and an optimally oriented

Copyright (C) The Society of Geomagnetism and Earth, Planetary and Space Sciences (SGEPSS); The Seismological Society of Japan; The Volcanological Society of Japan; The Geodetic Society of Japan; The Japanese Society for Planetary Sciences; TERRAPUB.

doi:10.5047/eps.2011.01.008 receiver fault. The specified receiver fault simply assumes that the receiver faults have the same strike, dip angle, and rake angle as the mainshock. Optimally oriented receiver faults are determined so as to maximize the $\triangle \mathrm{CFF}$ under the assumed local-regional stress field, taking into account the stress perturbation due to mainshocks (e.g., King et al., 1994).

Mueller et al. (2004) suggested that focal mechanisms of large historical earthquakes can be estimated from recent seismicity based on the $\triangle \mathrm{CFF}$. Using this approach, they estimated the focal regions and mechanisms of four earthquake sequences (magnitude $(M) \sim 7$ ) that occurred in New Madrid, MO, USA between 1811 and 1812. If recent seismicity actually does represent the aftershocks of these earthquakes, then aftershock activity has continued for 200 years. Utsu et al. (1995) reported that the number of felt earthquakes at Gifu, central Japan, obeyed the Omori formula (Omori, 1894) for a century after the 1891 Nobi earthquake ( $M$ 8.0) (Utsu, 1979). More recently, Stein and Liu (2009) suggested the possibility that aftershock activities continue for hundreds of years in a slowly deformed tectonic environment. However, although seismicity rate changes (aftershock activities) can continue for a long period, few studies have investigated the correlation between the $\triangle \mathrm{CFF}$ associated with large historical earthquakes and recent seismicity.

In Japan, small-magnitude earthquakes have been detected by a recently developed dense seismic network 


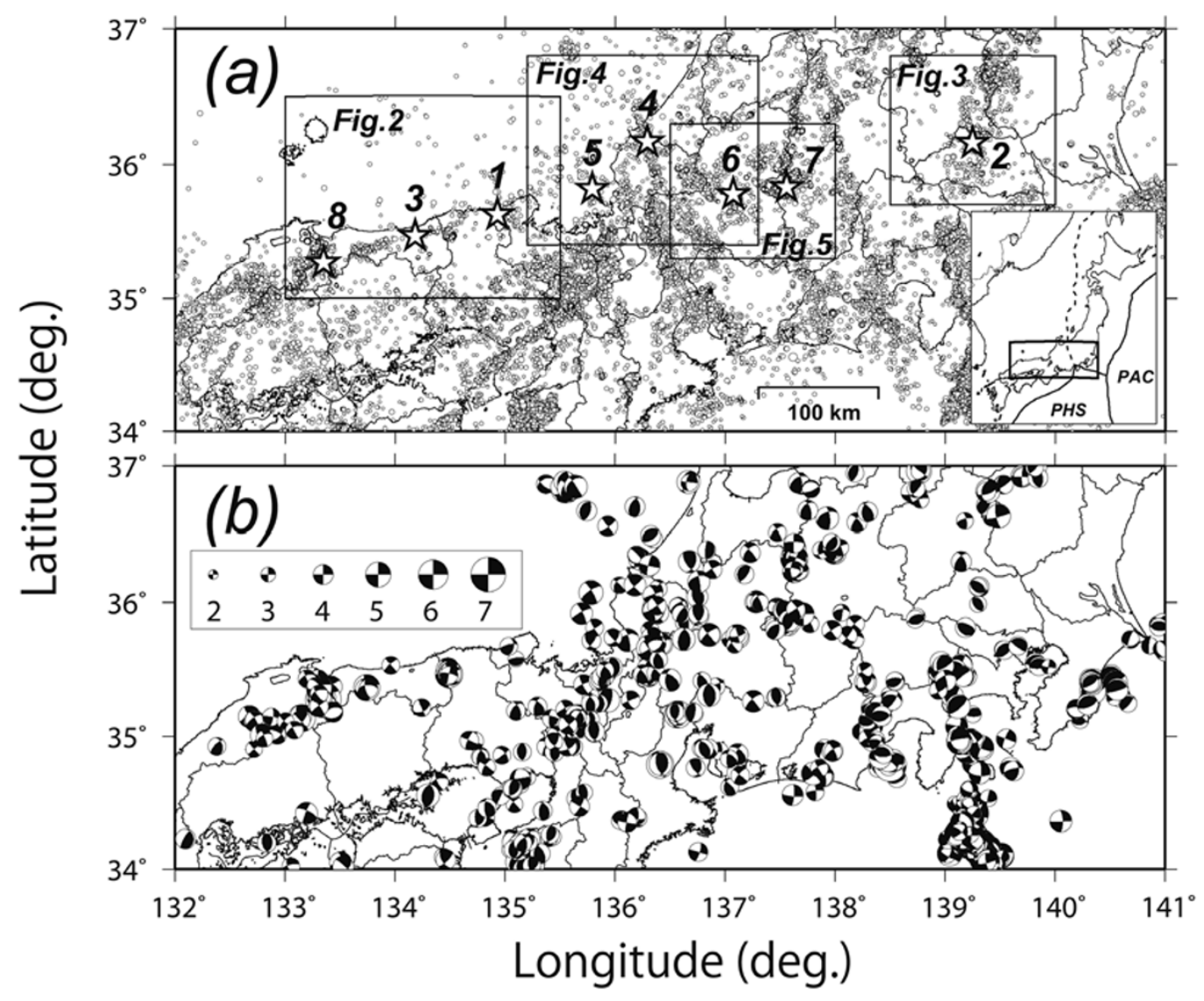

Fig. 1. (a) Epicentral distribution from the unified JMA catalog (October 1997 to May $2010, M \geq 1.5$, hypocentral depth $\leq 30 \mathrm{~km}$ ). The white stars denote the epicenters of eight large historical earthquakes with strike-slip fault mechanisms (1. the 1927 Tango earthquake ( $M$ 7.3), 2. the 1931 Nishi-Saitama earthquake ( $M$ 6.9), 3. the 1943 Tottori earthquake $(M 7.2), 4$. the 1948 Fukui earthquake ( $M 7.1), 5$. the 1963 Wakasa Bay earthquake ( $M$ 6.9), 6. the 1969 Gifu-Ken Chubu earthquake ( $M$ 6.6), 7. the 1984 Nagano-Ken Seibu earthquake ( $M$ 6.8), 8. the 2000 Tottori-Ken Seibu earthquake $(M 7.3)$ ). In the inset, PHS denotes the Philippine Sea Plate, and PAC denotes the Pacific Plate. The rectangles indicate the regions of subsequent figures (Figs. 2, 3, 4, and 5). (b) Distributions of the F-net focal mechanism solutions from October 1997 to May 2010 determined by NIED.

of high-sensitivity seismographs. Source processes of large historical earthquakes during the past century have been obtained from various seismological and/or geological datasets. In this study, we investigate the correlation between the $\triangle \mathrm{CFF}$ due to large historical earthquakes and recent seismicity. Our results suggest that the recent earthquake catalog possibly includes numerous aftershocks of some large historical earthquakes.

\section{Data}

We use the Japan Meteorological Agency (JMA) catalog from October 1997 to May 2010 (Fig. 1(a)) for recent seismicity. The completeness magnitude, above which all earthquakes are detected considered to be detected by a seismic network, has been estimated to be 1.0 for the Japanese mainland during this period (Ishibe, 2007; Schorlemmer et al., 2008; Ishigaki, 2009; Nanjo et al., 2010). The detection capability and accuracy of the hypocentral location have significantly improved since October 1997 due to the unification of earthquake observation data by JMA and the installation of a new high-sensitivity seismograph network in Japan (Hi-net) (Okada et al., 2004; Obara et al., 2005). The accuracy of the epicentral location is important for determining the spatial correlation between the current seismicity and $\triangle \mathrm{CFF}$; hence, we use shallow earthquakes (hypocentral depth $\leq 30 \mathrm{~km}$ ) with location uncertainties of $<2 \mathrm{~km}$.

We also use focal mechanism solutions of moderate earthquakes $(M \geq 2.5)$ from a catalog of the National Research Institute for Earth Science and Disaster Prevention (NIED) from October 1997 to May 2010. This catalog is based on the waveform data obtained by the FullRange Seismograph Network (F-net) (Fig. 1(b); Fukuyama et al., 1998). There are 2,271 focal mechanisms in Fig. 1(b). Hereafter, we refer to these focal mechanism solutions as F-net solutions.

We select eight large $(M \geq 6.5)$ shallow, historical (since 1923 ) earthquakes with strike-slip fault mechanisms on the Japanese inland (Fig. 1(a)). We exclude the Izu region because a complicated stress disturbance is expected due to the occurrence of frequent large earthquakes since 1923 (e.g., the 1930 Kita-Izu earthquake (M 7.3), the 1974 IzuHanto-Oki earthquake ( $M$ 6.9)) and magma intrusion (Toda et al., 2002). We use the fault parameters estimated by previous seismological and/or geological studies (Table 1). 


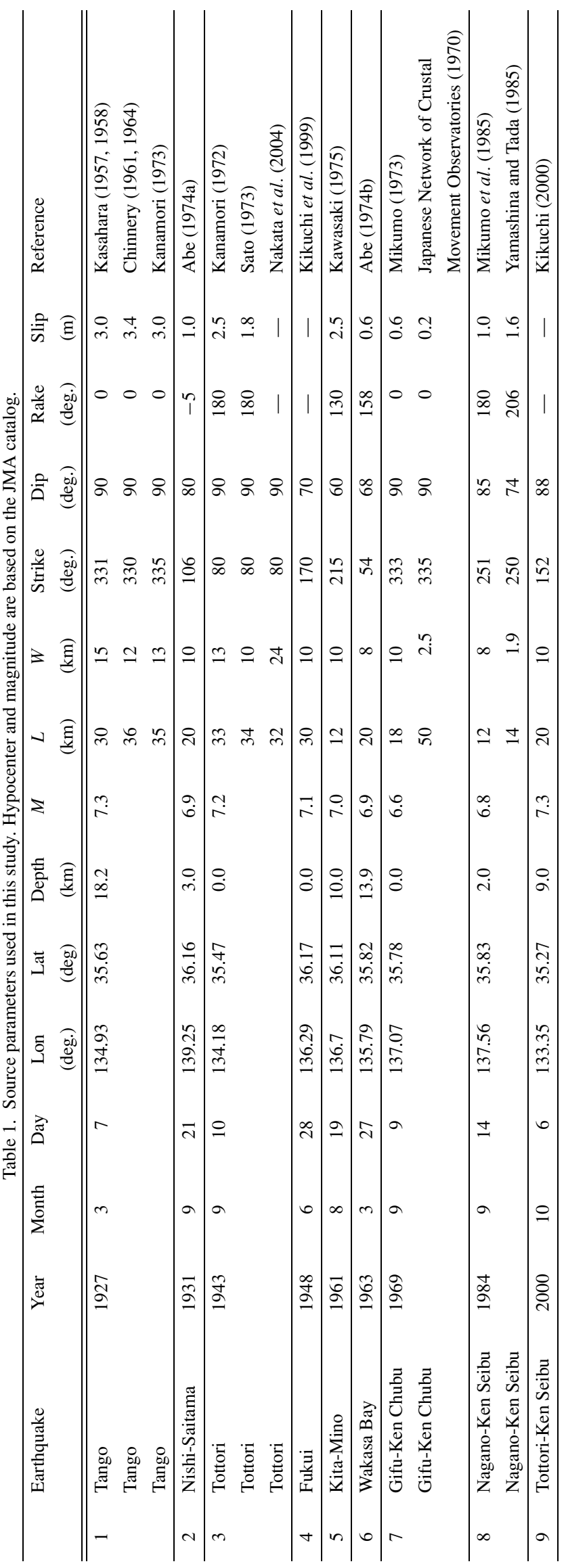




\section{Method}

In our calculation of the $\triangle \mathrm{CFF}$ associated with large historical earthquakes, we assume an elastic half-space, an apparent coefficient of friction of 0.4 , a shear modulus of $32 \mathrm{GPa}$, and a Poisson's ratio of 0.25 . Multiple fault models have been proposed for some earthquakes; for these earthquakes, we investigate how uncertainty due to different fault parameters affects the results.

We calculate $\triangle \mathrm{CFF}$ for two types of receiver faults: the mainshock solution and the F-net solutions. For the mainshock focal mechanism receiver fault, the calculation depth is basically set at the center of the fault plane. The calculated $\triangle \mathrm{CFF}$ is compared with the distribution of recent earthquakes to determine if a spatial correlation exists. Strike-slip faults are basically nearly vertical, and the depth changes in the $\triangle \mathrm{CFF}$ are small; hence, the $\triangle \mathrm{CFF}$ distribution is robust. Spatial heterogeneity of earthquake detection capability can be neglected because of the relatively small target region; hence, we use all of the earthquakes in the catalog without setting a magnitude threshold. We have verified that the conclusion does not change whether the completeness magnitude is considered or not.

Calculation of the $\triangle \mathrm{CFF}$ for assumed receiver faults may generate large errors under a complex regional stress field in which various types of earthquakes occur, and this uncertainty can be substantially reduced by using focal mechanisms as receiver faults (e.g., Toda, 2008). Thus, we also calculate the $\triangle \mathrm{CFF}$ associated with large historical earthquakes for receiver faults of the F-net solutions. For earthquakes that occurred prior to the 2000 Tottori-Ken Seibu earthquake, we do not include the $\triangle \mathrm{CFF}$ due to this earthquake.

We set the lowest and highest $\triangle \mathrm{CFF}$ thresholds. For low absolute $\triangle \mathrm{CFF}$ values, the sign can easily reverse (e.g., because of errors in hypocentral location). Furthermore, the number of earthquakes with low absolute $\triangle \mathrm{CFF}$ values depends on the spatial extent of the study area. If we adopt a very broad region, the $\triangle \mathrm{CFF}$ values of almost all of the earthquakes are nearly zero, leading to the conclusion that recent seismicity is not correlated with the $\triangle \mathrm{CFF}$ associated with large historical earthquakes. Thus, we omit earthquakes with absolute $\triangle \mathrm{CFF}$ values of $<0.1$ bars, which is the minimum threshold commonly associated with static stress triggering (e.g., Reasenberg and Simpson, 1992; Hardebeck et al., 1998; Harris, 1998). However, significantly high absolute $\triangle \mathrm{CFF}$ values, which can be observed to be very close to rupture faults, may have large uncertainties, perhaps because of simplified source geometry and slip distribution. Therefore, we also omit earthquakes with absolute $\Delta \mathrm{CFF}$ values $>15$ bars and those that occurred within $5 \mathrm{~km}$ of the rupture source faults.

\section{Results}

4.1 Spatial correlation between recent seismicity and $\triangle \mathrm{CFF}$ for mainshock receiver faults

4.1.1 1927 Tango (M 7.3), 1943 Tottori (M 7.2), and 2000 Tottori-Ken Seibu $(M 7.3)$ earthquakes The Tango earthquake occurred on March 7, 1927, in the Tango district, located $90 \mathrm{~km}$ northwest of Kyoto City, causing large-scale damage $(14,405$ completely collapsed or burnt houses and 2,908 fatalities) in the surrounding region (e.g., Yamasaki and Tada, 1928). We use the fault model based on Kasahara $(1957,1958)$ to calculate the $\triangle \mathrm{CFF}$. The Tottori earthquake, which occurred on September 10, 1943, in the eastern part of the Tottori Prefecture, southwestern Honshu, resulted in 1,083 fatalities and 7,485 collapsed houses. In this case, we adopt the variable slip model estimated by Nakata et al. (2004), who estimated the slip distribution based on strong motion seismographs (Fig. 2(a)). In the neighboring region, the Tottori-Ken Seibu earthquake occurred on October 6, 2000, and here we adopt the variable slip model estimated by Kikuchi (2000) (Fig. 2(b)).

Figure 2(c) depicts the epicentral distribution of recent seismicity from the unified JMA catalog and the $\triangle \mathrm{CFF}$ associated with these three earthquakes; recent seismicity can be seen to significantly concentrate on the positive $\Delta \mathrm{CFF}$ regions, especially in the eastern and western extents of the 1943 Tottori earthquake source fault. The fault mechanism of the Tottori earthquake is assumed to be a receiver fault mechanism, although the result is almost the same whether the fault mechanism of the 1927 Tango or that of the 2000 Tottori-Ken Seibu earthquake is used because they occurred on conjugate fault systems. The spatial correlations between the positive $\triangle \mathrm{CFF}$ regions and recent seismicity are also found even if other fault models (e.g., Chinnery, 1961, 1964; Kanamori, 1972, 1973; Sato, 1973) are used as a source fault. Linear seismic activity along the source faults can be recognized. The Kita-Tajima earthquake ( $M$ 6.8) occurred on May 23, 1925, between the source region of the Tango and Tottori earthquakes, and current seismicity may include the aftershocks of this earthquake. Inclusion of the $\triangle \mathrm{CFF}$ due to this earthquake in the analysis may enable a more reliable analysis; however, the detailed rupture process has not been revealed. The 1927 Tango earthquake increased the $\triangle \mathrm{CFF}$ at the hypocenter of both the 1943 Tottori and the 1963 Wakasa Bay earthquakes (discussed later); the 1943 Tottori earthquake increased the $\Delta \mathrm{CFF}$ by 0.1 bars at the hypocenter of the 2000 Tottori-Ken Seibu earthquake, and thus probably accelerated the earthquake occurrences.

4.1.2 1931 Nishi-Saitama earthquake (M 6.9) The Nishi-Saitama earthquake, which occurred on September 21, 1931, resulted in 16 fatalities and 206 collapsed houses. It has been estimated that the hypocenter is at Yorii, Osato, Saitama Prefecture and the focal mechanism is a left-lateral strike-slip motion on an E-W trending fault with a length of $20 \mathrm{~km}$ (Abe, 1974a). Figure 3 depicts the recent epicentral distribution and the $\triangle \mathrm{CFF}$ associated with this earthquake. No significant correlation between positive $\triangle \mathrm{CFF}$ regions and recent seismicity is observed, although the seismic cluster in the northeastern part from the source fault is concentrated in positive $\triangle \mathrm{CFF}$ regions.

4.1.3 1948 Fukui (M 7.1) and 1963 Wakasa Bay (M 6.9) earthquakes The Fukui earthquake occurred on June 28, 1948, near Fukui City in western central Honshu. It destroyed 36,000 houses and caused 3,769 fatalities. We adopt the variable slip model of Kikuchi et al. (1999), who analyzed the source process using low-gain strong motion seismographs and obtained a left-lateral motion on a fault striking almost NNW-SSE and dipping to the west (Fig. 4(a)). In the adjacent region, the Wakasa Bay earth- 


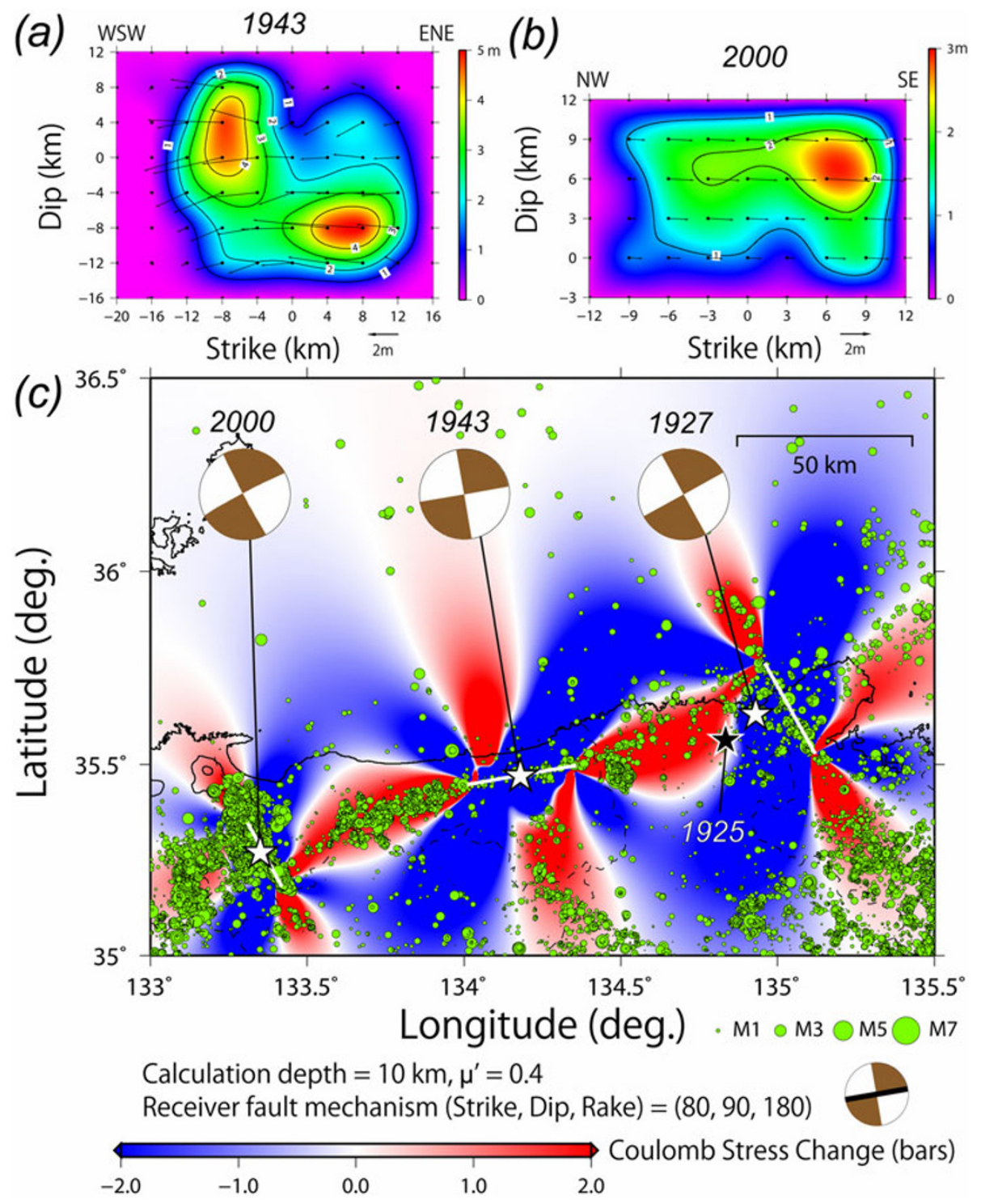

Fig. 2. (a) Slip distribution of the Tottori earthquake by Nakata et al. (2004). (b) Slip distribution of the Tottori-Ken Seibu earthquake by Kikuchi (2000). (c) The $\triangle$ CFF associated with three large earthquakes (the 1927 Tango, 1943 Tottori, and 2000 Tottori-Ken Seibu earthquakes) and recent seismicity. The stars indicate epicenters determined by JMA. The black star indicates the epicenter of the 1925 Kita-Tajima earthquake. The focal mechanisms are based on Kasahara $(1957,1958)$ for the Tango, Nakata et al. (2004) for the Tottori, and Kikuchi (2000) for the Tottori-Ken Seibu earthquake. The white lines indicate the faults of each earthquake projected on the surface. The bold line in the bottom-right focal mechanism indicates the nodal plane of the receiver fault mechanism. The green circles indicate hypocenters, based on the unified JMA catalog (from October 1997 to May 2010, all magnitudes, depth $\leq 30 \mathrm{~km}$ ).

quake occurred on March 26, 1963, north of Kyoto, near the northwest coast of the Japan Sea. We adopt the fault model of Abe (1974b), who determined dynamic and static fault parameters by directly comparing synthetic and observed seismograms at both near and far distances. The Tango earthquake $(M 7.3)$ of 1927, the Kita-Mino earthquake ( $M$ 7.0) of 1961, and the Gifu-Ken Chubu earthquake (M 6.6) of 1969 (discussed later) occurred in the neighboring region; therefore, the $\triangle \mathrm{CFF}$ associated with these earthquakes are also considered. We adopt the fault model of Kawasaki (1975), who concluded that the Kita-Mino earthquake resulted from a combination of right-lateral and reverse motions on the Hatogayu-Koike fault.

Figure 4(b) depicts the epicentral distribution of recent earthquakes and the $\triangle \mathrm{CFF}$ due to the 1927 Tango, 1948 Fukui, 1961 Kita-Mino, 1963 Wakasa Bay, and 1969 Gifu-
Ken Chubu earthquakes, assuming the focal mechanism of the Fukui earthquake as a receiver fault mechanism. Around the source region of the Fukui earthquake, positive $\triangle$ CFF regions correlate well with recent seismicity, suggesting that the $\triangle \mathrm{CFF}$ associated with the Fukui earthquake still affects recent seismicity. However, no significant correspondence between recent seismicity and positive $\triangle \mathrm{CFF}$ regions can be observed around the source region of the 1963 Wakasa Bay earthquake, even if the focal mechanism of the Wakasa Bay earthquake is assumed to be a receiver fault mechanism. Seismic activity around the Wakasa Bay earthquake is significantly quiet compared with that of the surrounding region, indicating that a seismic gap exists and suggesting that the aftershock activity of the Wakasa Bay earthquake has returned to the background seismicity level. 


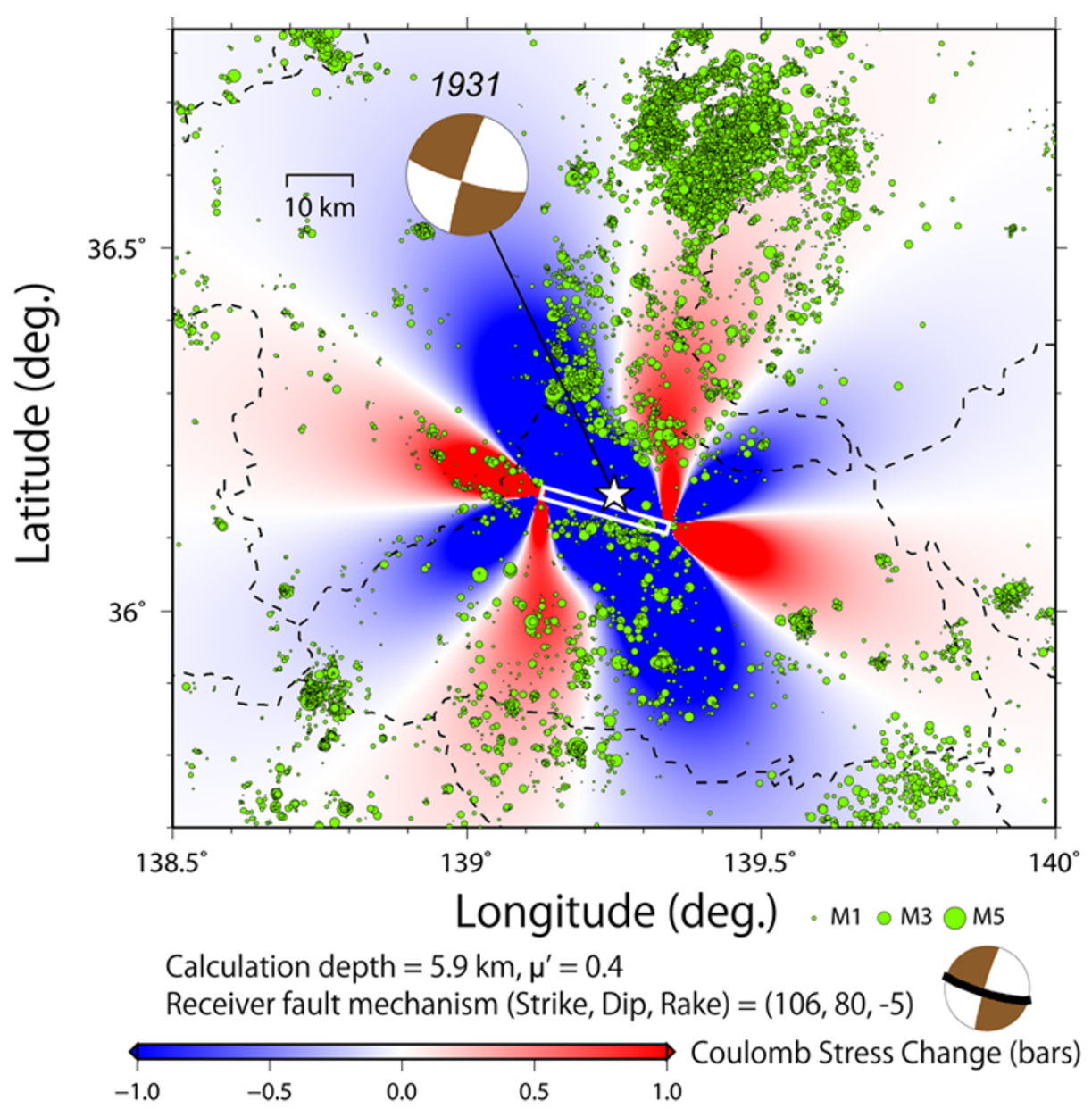

Fig. 3. The $\triangle \mathrm{CFF}$ associated with the Nishi-Saitama earthquake and recent seismicity. The focal mechanism of the mainshock is based on Abe (1974a). The symbols are the same as in Fig. 2.

4.1.4 1969 Gifu-Ken Chubu (M 6.6) and 1984 Nagano-Ken Seibu ( $M$ 6.8) earthquakes The Gifu-Ken Chubu earthquake occurred on September 9, 1969, and the Nagano-Ken Seibu earthquake occurred on September 14, 1984, in central Honshu. We adopt the fault models of Mikumo (1973) and Mikumo et al. (1985).

Figure 5 depicts the recent epicentral distribution and the $\triangle \mathrm{CFF}$ associated with these earthquakes. The $\triangle \mathrm{CFF}$ associated with the 1961 Kita-Mino earthquake is also considered. No significant correspondences are observedeven when other fault models are adopted (e.g., the Japanese Network of Crustal Movement Observatories, 1970; Yamashina and Tada, 1985). This result suggests that the aftershock activity has already returned to the background seismicity level, similar to the 1963 Wakasa Bay earthquake.

\subsection{Correlation between recent seismicity and $\triangle \mathrm{CFF}$ for F-net focal mechanism solutions}

Figure 6 depicts the $\triangle \mathrm{CFF}$ due to nine large historical earthquakes (the eight earthquakes plus the 1961 Kita-Mino earthquake), calculated at the hypocenters, and the F-net solutions of recent moderate earthquakes. This figure clearly indicates that the majority of earthquakes occur in positive $\triangle \mathrm{CFF}$ regions and that recent moderate earthquakes have possibly been affected by historical large earthquakes. This result is basically consistent with results for the main- shock receiver fault mechanisms in the source regions of the 1927 Tango, 1943 Tottori, 1948 Fukui, and 2000 TottoriKen Seibu earthquakes. The focal mechanisms of earthquakes around the source regions of the Tango, Tottori, and Tottori-Ken Seibu earthquakes are dominantly the strikeslip type, striking NNW-SSE or WSW-ENE, similar to the focal mechanisms of these mainshocks. However, this figure also indicates the difficulty in calculating the $\triangle \mathrm{CFF}$ by assuming one specified receiver fault mechanism in a complex regional stress field in which earthquakes with various focal mechanisms occur. The focal mechanisms of the earthquakes around the 1931 Nishi-Saitama, 1963 Wakasa Bay, 1969 Gifu-Ken Chubu, and 1984 Nagano-Ken Seibu earthquakes exhibit mixtures of thrust and strike-slip types. A typical example is an earthquake swarm in the northeastern part of the Nagano-Ken Seibu earthquake source region, which occurred in a negative $\triangle \mathrm{CFF}$ region (Fig. 7(a)). However, focal mechanisms of most earthquakes in this swarm are of the thrust type (Fig. 7(b)); therefore, the mainshock receiver fault mechanism fails to evaluate the $\triangle \mathrm{CFF}$ for the swarm. Figure 7(b) also depicts the $\triangle \mathrm{CFF}$ on a thrust receiver fault mechanism and with a low apparent coefficient of friction $\left(\mu^{\prime}=0.1\right)$. Because the existence of free water dehydrated from magma is suggested from the resistivity structure (e.g., Kasaya et al., 2002), the apparent coefficient of friction may be low due to the increase of 
(a)

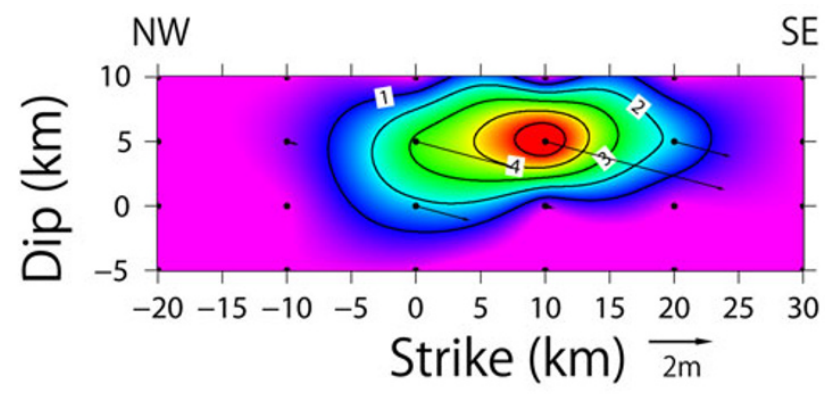

(b)

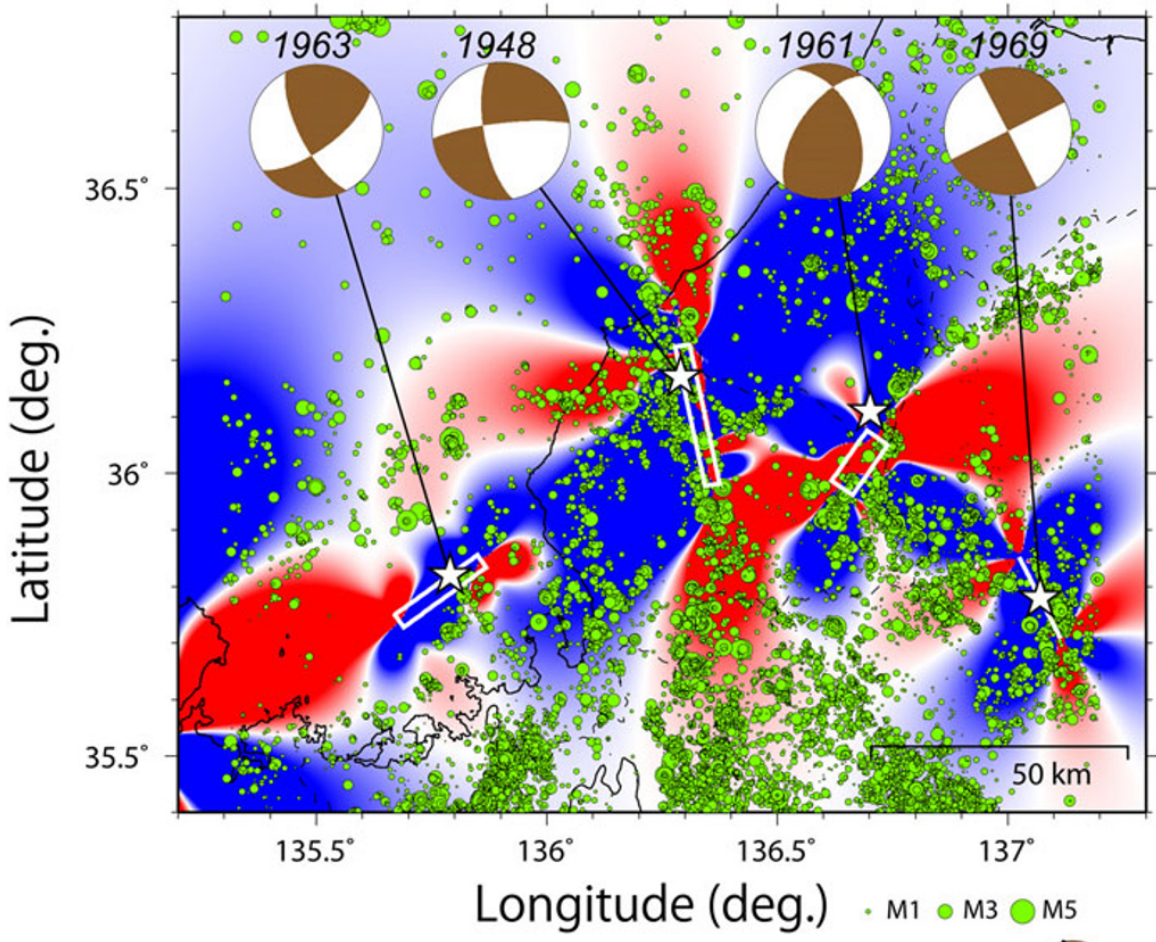

Calculation depth $=7.7 \mathrm{~km}, \mu^{\prime}=0.4$

Receiver fault mechanism (Strike, Dip, Rake) $=(170,70,-10)$

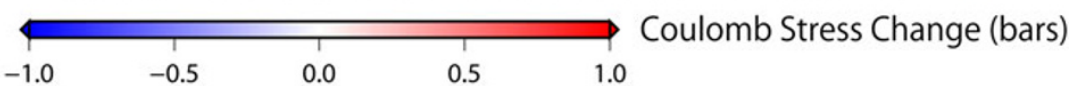

Fig. 4. (a) Slip distribution of the Fukui earthquake by Kikuchi et al. (1999). (b) The $\Delta$ CFF associated with five large earthquakes (the 1927 Tango, 1948 Fukui, 1961 Kita-Mino, 1963 Wakasa Bay, and 1969 Gifu-Ken Chubu earthquakes). The focal mechanisms are based on Kikuchi et al. (1999) for the Fukui, Kawasaki (1975) for the Kita-Mino, Abe (1974b) for the Wakasa Bay, and Mikumo (1973) for the Gifu-Ken Chubu earthquakes. The symbols are the same as in Fig. 2.

pore pressure. The positive $\triangle \mathrm{CFF}$ region to the northeast of the source fault correlates well with recent seismicity, although the pore pressure changes accompanying fluid migration may be a major factor contributing to seismicity rate changes.

The probability distribution of earthquakes as a function of the $\triangle \mathrm{CFF}$ (Fig. 8) indicates that moderate earthquakes place a disproportionate emphasis on positive $\triangle \mathrm{CFF}$ values. If the first/second nodal plane of the F-net solutions is assumed to be the receiver fault mechanism (the total number of earthquakes is $211 / 210$ ), the number of earthquakes with positive $\triangle \mathrm{CFF}$ is $123 / 123(\sim 60 \%)$, and the number of earthquakes with negative $\Delta \mathrm{CFF}$ is $88 / 87(\sim 40 \%)$. In this figure, earthquakes that occurred in the rectangular regions in Fig. 6 are used because the $\triangle \mathrm{CFF}$ associated with other large earthquakes is probably a dominant factor contributing to seismicity in other regions. However, a concentration of focal mechanisms in positive $\triangle \mathrm{CFF}$ regions is observed even if we include all earthquakes. This result implies that stress perturbations due to some historical large earthquakes still affect recent seismicity.

\section{Discussion}

5.1 Possible factors generating uncertainties in estimating the $\triangle \mathrm{CFF}$

Recent seismicity correlates well with the positive $\Delta \mathrm{CFF}$ regions associated with the four large historical earthquakes (the 1927 Tango, 1943 Tottori, 1948 Fukui, and 2000 Tottori-Ken Seibu earthquakes), but no distinct correlations are found for the other four earthquakes (the 1931 Nishi- 


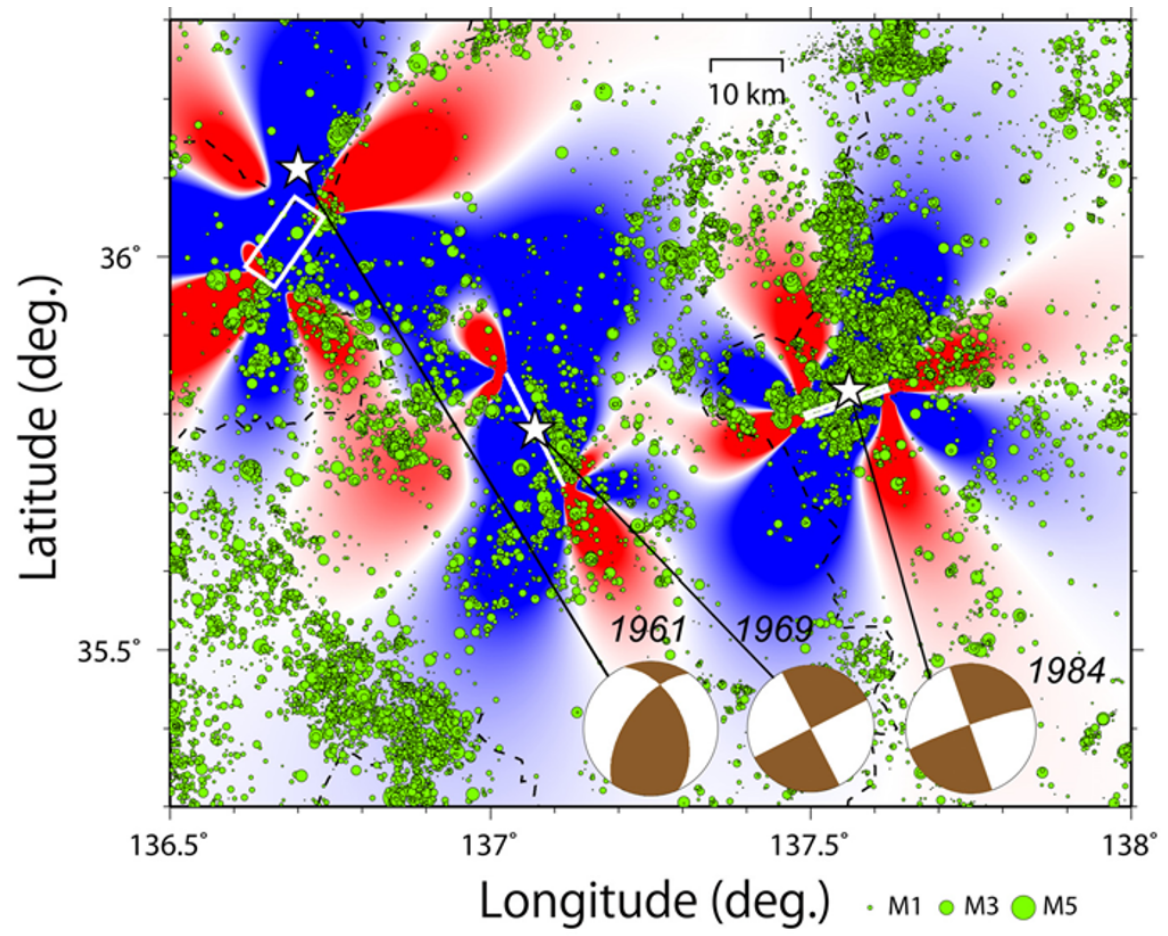

Calculation depth $=5 \mathrm{~km}, \mu^{\prime}=0.4$

Receiver fault mechanism (Strike, Dip, Rake) $=(251,85,180)$

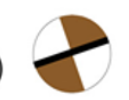

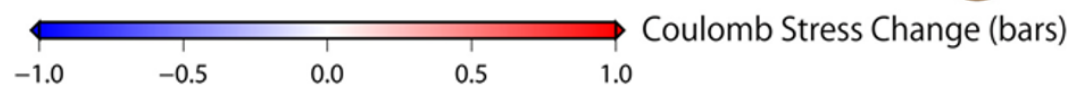

Fig. 5. The $\triangle \mathrm{CFF}$ associated with three large earthquakes that occurred in central Japan (the 1961 Kita-Mino, 1969 Gifu-Ken Chubu, and 1984 Nagano-Ken Seibu earthquakes) and recent seismicity. The focal mechanisms are based on Kawasaki (1975) for the Kita-Mino, Mikumo (1973) for the Gifu-Ken Chubu, and Mikumo et al. (1985) for the Nagano-Ken Seibu earthquakes. The symbols are the same as in Fig. 2.

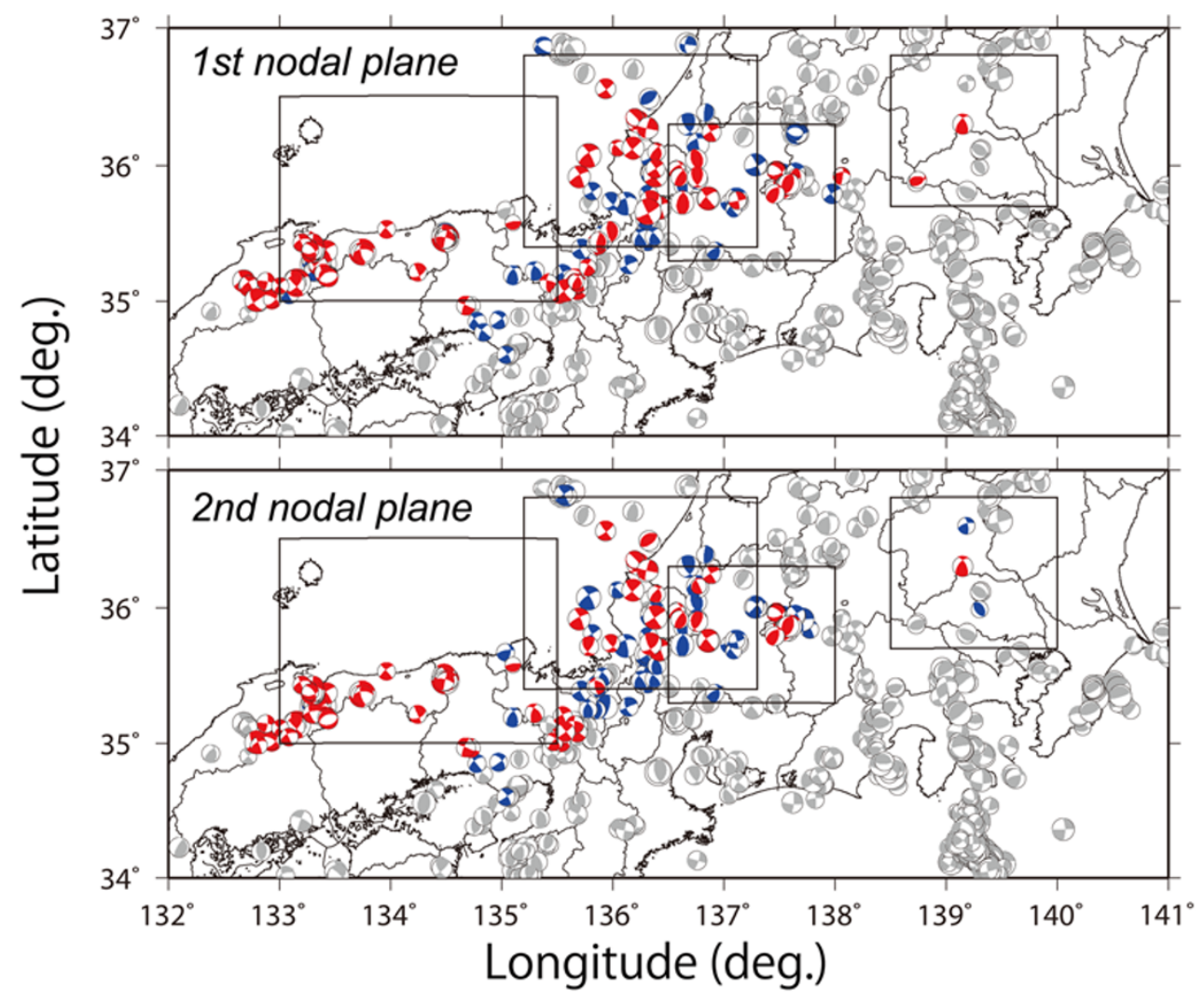

Fig. 6. Signs of the $\triangle \mathrm{CFF}$ calculated on the two nodal planes of F-net solutions. The red (blue) focal mechanism indicates the positive (negative) values of the calculated $\triangle \mathrm{CFF}$. Grey denotes the focal mechanisms for which the absolute value of the calculated $\Delta \mathrm{CFF}$ is 0.1 bars or less. 


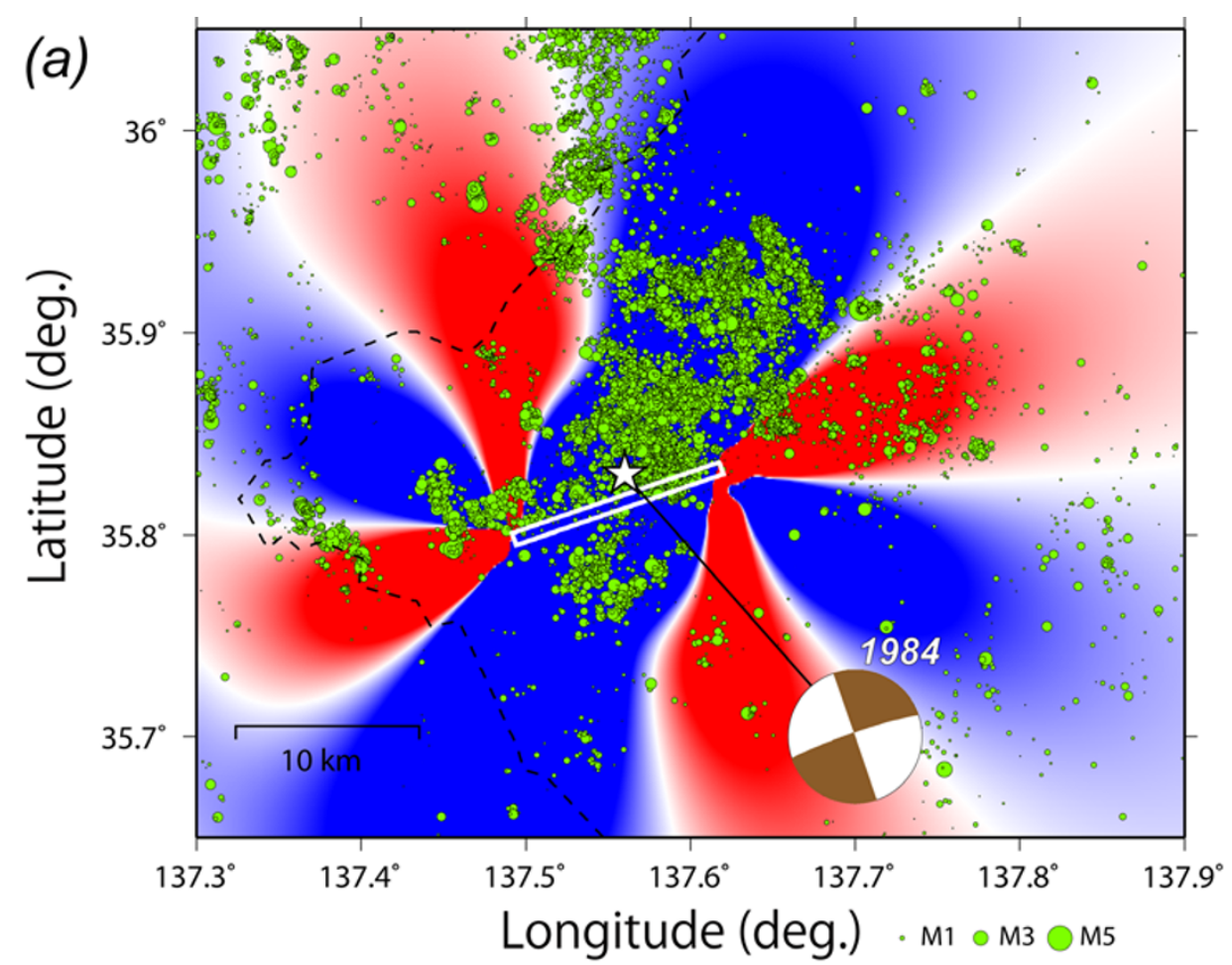

Calculation depth $=5 \mathrm{~km}, \mu^{\prime}=0.4$

Receiver fault mechanism (Strike, Dip, Rake) $=(251,85,180)$

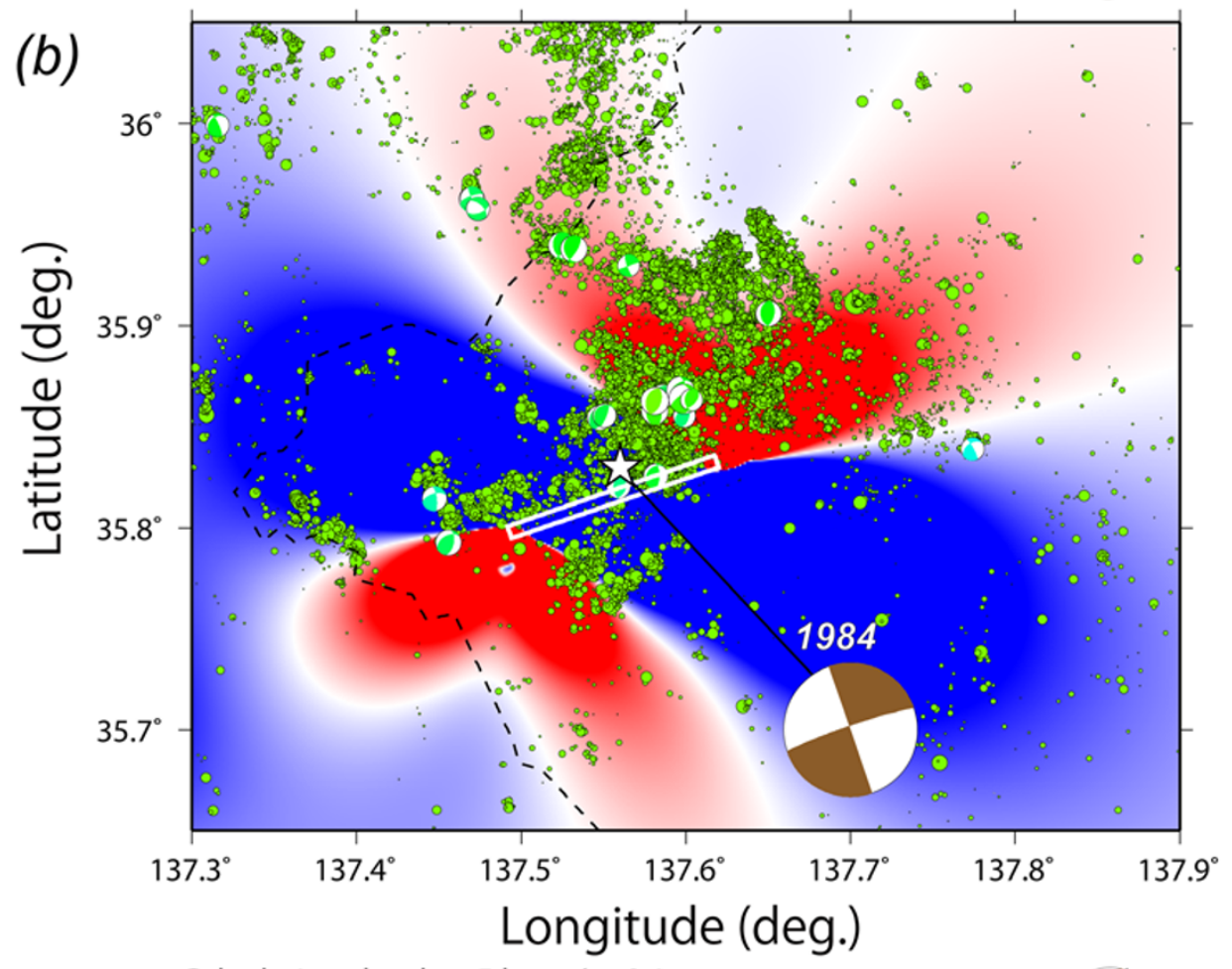

Calculation depth $=5 \mathrm{~km}, \mu^{\prime}=0.1$

Receiver fault mechanism (Strike, Dip, Rake) $=(20,52,92)$

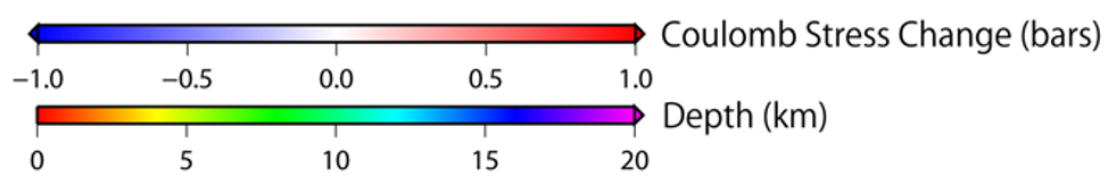

Fig. 7. (a) The $\triangle$ CFF associated with three large earthquakes that occurred in central Japan (the 1961 Kita-Mino, 1969 Gifu-Ken Chubu, and 1984 Nagano-Ken Seibu earthquakes) and recent seismicity. The assumed receiver fault mechanism is the mainshock of the 1984 Nagano-Ken Seibu earthquake. (b) Distributions of F-net solutions from October 1997 to May 2010. The $\Delta$ CFF assuming a thrust-type earthquake as a receiver fault mechanism and a low apparent coefficient of friction is also indicated. The other symbols are the same as in Fig. 2. 


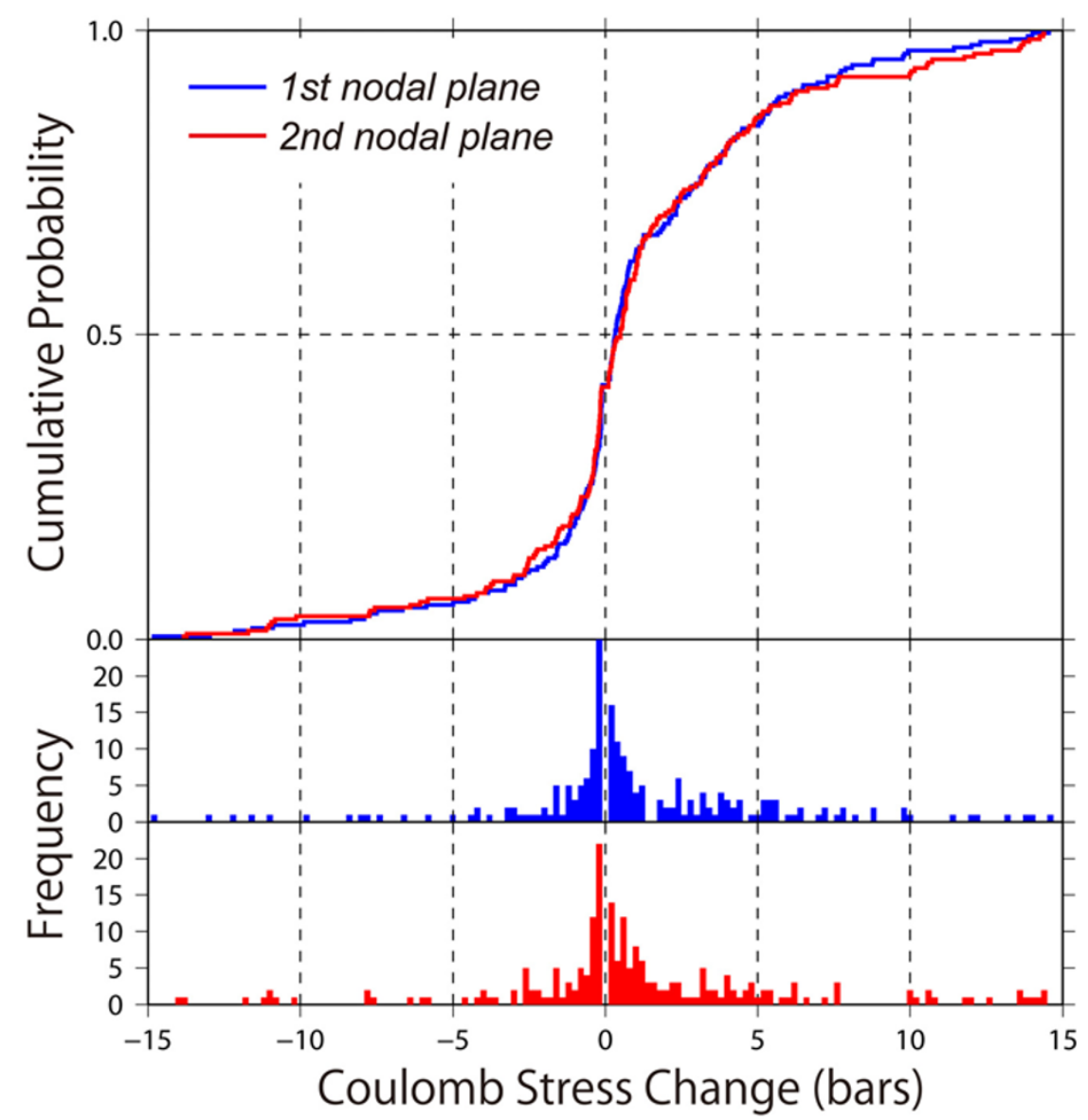

Fig. 8. Cumulative probability distribution of earthquakes with the $\triangle \mathrm{CFF}$ resolved on two nodal planes. The horizontal axis indicates the $\triangle \mathrm{CFF}$ associated with nine large historical earthquakes (the 1927 Tango, 1931 Nishi-Saitama, 1943 Tottori, 1948 Fukui, 1961 Kita-Mino, 1963 Wakasa Bay, 1969 Gifu-Ken Chubu, 1984 Nagano-Ken Seibu, and 2000 Tottori-Ken Seibu earthquakes). The vertical axis indicates the cumulative probability distribution normalized by the total number of earthquakes. The two lower panels depict the frequency histograms of the $\Delta \mathrm{CFF}$ calculated on the first/second nodal plane.

Saitama, 1963 Wakasa Bay, 1969 Gifu-Ken Chubu, and 1984 Nagano-Ken-Seibu earthquakes) in terms of the mainshock receiver faults. Furthermore, the probability distribution of moderate earthquakes plotted against the $\triangle \mathrm{CFF}$ clearly indicates that recent earthquakes concentrate in positive $\triangle \mathrm{CFF}$ regions. However, a number of possible factors generate uncertainties in the correlation between the $\Delta \mathrm{CFF}$ and recent seismicity.

One possible factor is the simplicity of the model. First, the $\triangle \mathrm{CFF}$ associated with the 1927 Tango, 1931 NishiSaitama, 1963 Wakasa Bay, 1969 Gifu-Ken Chubu, and 1984 Nagano-Ken Seibu earthquakes are calculated using uniform slip models. More reliable discussion will be possible using variable slip models.

Second, the background seismicity rate is assumed to be uniform throughout the target region, in comparison with the $\triangle \mathrm{CFF}$ and recent seismicity. The $\triangle \mathrm{CFF}$ can be quantitatively correlated with changes from the background seismicity rate using earthquake and/or focal mechanism catalogs before and after large earthquakes (e.g., Dietrich, 1994; Aoi et al., 2010). However, estimating a spatially heterogeneous background seismicity rate is not straightforward because of inadequate knowledge on small-magnitude earthquakes and focal mechanisms in earlier catalog duration, and the short reference period. For example, the available catalog duration is only 4 years for the 1927 Tango earthquake because the JMA catalog started in 1923. Based on this scarcity of data, we are therefore not able to absolutely deny that it may be purely coincidental that positive $\Delta \mathrm{CFF}$ regions associated with large historical earthquakes match high background seismicity rate zones.

Third, spatial heterogeneity of the receiver fault mechanism is not considered for the mainshock receiver faults. Our study findings clearly indicate that the specified receiver fault mechanism may generate large errors and sometimes fail to obtain fair conclusions in a complex regional stress field, and that this uncertainty can be substantially reduced by using F-net solutions as receiver faults.

Fourth, the temporal decay dependence on the lapse time from the mainshock is neglected. Decay of aftershock activities is known to be expressed by the Omori-Utsu law (Utsu, 1961), and the seismicity rate change after a large earthquake can be described using the rate- and state-dependent friction law (e.g., Dietrich, 1994). Aftershock activity and stress perturbation accompanying large earthquakes decay with time, and a better quantitative analysis can be performed by considering this effects (e.g., Toda and Enescu, 2011).

Another possible factor affecting uncertainties in estimating the $\triangle \mathrm{CFF}$ is aftershock decay to background seismicity 
level. Aftershock decay time, $t_{\mathrm{a}}$, can be represented as follows, using the constitutive parameter in the rate- and statedependent friction law $A$, total normal stress applied to fault plane $\sigma$ and shear stress rate $\bar{\tau}$ (Dietrich, 1994):

$$
t_{\mathrm{a}}=\frac{A \sigma}{\bar{\tau}}
$$

Thus, aftershock decay time is inversely proportional to shear stress rate, indicating that aftershock activity can continue for a long time in slowly deformed tectonic environments. The shear stress rate in the source regions of the 1927 Tango, 1943 Tottori, and 2000 Tottori-Ken Seibu earthquakes, for which a distinct correlation between positive $\triangle \mathrm{CFF}$ regions and recent seismicity was observed, is estimated to be relatively lower than that in the source regions of the other earthquakes (Sagiya et al., 2000).

Other stress changes (e.g., dynamic stress changes and/or pore-pressure changes accompanying fluid migration) may also be major factors controlling seismicity rate changes. More recent large earthquakes may load on top of the $\triangle \mathrm{CFF}$ associated with large historical earthquakes and mask it, even if changes from the background seismicity rate continue.

\subsection{Effect on reliable estimation of background seis- micity rate}

Background seismicity rate, a fundamental parameter describing seismicity, can be used to forecast future earthquakes because anomalous seismicity (e.g., seismic quiescence or activation prior to large earthquakes) has been recognized as a deviation from background seismicity rate (e.g., Inouye, 1965; Utsu, 1968; Mogi, 1969; Kelleher and Savino, 1975; Ohtake et al., 1977; Habermann and Wyss, 1984; Wyss, 1986; Kisslinger, 1988; Taylor et al., 1991; Imoto, 1992; Miyaoka and Yoshida, 1993; Odaka and Maeda, 1994; Wiemer and Wyss, 1994; Takanami et al., 1996; Katsumata and Kasahara, 1999; Enescu and Ito, 2001; Huang et al., 2001; Huang and Nagao, 2002). Furthermore, various earthquake forecasting models based on the background seismicity rate have been proposed in the Collaboratory for the Study of Earthquake Predictability (CSEP), which was recently started in Japan (Nanjo et al., 2011; Tsuruoka et al., 2011). Reliable estimation of the background seismicity rate is essential for detecting such anomalous seismicity and for testing such forecast models.

However, the definition and the measurement of background seismicity rate are still controversial, and different approaches are used in the literature (e.g., Hainzl and Ogata, 2005). Cocco et al. (2010) recently redefined background seismicity rate as a time-independent smoothed seismicity rate estimated in a prescribed time window using a declustered catalog, and reference seismicity rate as a timeindependent smoothed seismicity rate estimated using an undeclustered catalog. These authors investigated the effects of the two approaches on seismicity forecasts.

Reliable and unbiased estimations of background seismicity rate are sometimes accompanied by various difficulties. For example, earthquake catalogs may include artificial seismicity rate changes (e.g., installation or closure of seismic stations, changes of instrument for seismic observation, and systematic changes in the magnitudes as- signed to events) (Habermann, 1981, 1982a, b, 1983, 1987, 1991; Perez and Scholtz, 1984; Wyss and Burford, 1985; Katsumata and Kasahara, 2004; Katsumata, 2006). Eneva et al. (1994) carefully investigated seismicity rate changes in the Garm district, Tajikistan, and concluded that most seismicity rate changes are artificial.

Another difficulty is the limitation of earthquake catalog duration. Large earthquakes change the stress field in the surrounding region and generate numerous smallermagnitude earthquakes, or aftershocks. Various declustering algorithms classifying earthquakes into background or triggered seismicity (aftershocks) have been investigated (e.g., Reasenberg, 1985; Zhuang et al., 2002). Such declustering may not suffer much when the contribution of historical earthquakes is not included because many earthquakes are actually triggered by more recent smaller neighboring events. However, significant correlations between the $\triangle \mathrm{CFF}$ and recent seismicity for some large historical earthquakes strongly suggest that the background seismicity rate estimated from earthquake catalogs is possibly affected by a number of large earthquakes that occurred prior to the start of the catalog. This is consistent with the findings of Helmstetter and Sornette (2003), who reported that many earthquakes included in an earthquake catalog are indeed secondary or higher aftershocks. The background seismicity rate estimated from a region activated/deactivated by large historical earthquakes may produce apparent seismic quiescence/activation accompanied by temporal decay. Thus, the availability of forecast models based on background seismicity rate may be reduced.

\section{Concluding Remarks}

In the study reported here, we investigated the spatial correlation between recent seismicity in Japan and the $\triangle \mathrm{CFF}$ associated with large historical earthquakes (since 1923, $M \geq 6.5$ ) with strike-slip mechanisms. The recent epicentral distribution correlates well with the positive $\triangle \mathrm{CFF}$ regions associated with four earthquakes (the 1927 Tango, 1943 Tottori, 1948 Fukui, and 2000 TottoriKen Seibu earthquakes). However, no significant correlations are observed for the other four earthquakes (the 1931 Nishi-Saitama, 1963 Wakasa Bay, 1969 Gifu-Ken-Chubu, and 1984 Nagano-Ken-Seibu earthquakes). The probability distribution of earthquakes with F-net solutions places a disproportionate emphasis on positive $\triangle \mathrm{CFF}$ values. These results suggest that recent seismicity is possibly still affected by a number of large historical earthquakes and that the aftershock decay time strongly depends on each earthquake.

The $\triangle \mathrm{CFF}$ calculated for a specified fault mechanism involves large uncertainty or fails to evaluate the correlation in complex stress fields (e.g., the 1984 Nagano-Ken Seibu earthquake source region). This study clearly indicates that this uncertainty could be substantially reduced by using F-net solutions of moderate earthquakes as receiver faults. The use of focal mechanism solutions of smaller earthquakes would enable more quantitative analyses; thus, a focal mechanism catalog that includes small-magnitude earthquakes is very important. Stress perturbation due to large earthquakes may shift the earthquake distribution for $\triangle \mathrm{CFF}$ to a positive side after the mainshocks, under the 
temporally stable observation network system and station distribution.

The background seismicity rate estimated from a region activated by large earthquakes may produce apparent seismic quiescence accompanied by temporal decay, and vice versa. Therefore, those effects may be important for more reliable and unbiased estimates of background seismicity rate using an earthquake catalog, especially a relatively short catalog.

Acknowledgments. We thank Dr. Ross Stein and an anonymous reviewer, who gave us thoughtful and relevant comments and suggestions to improve this manuscript. We also thank Drs. Shinji Toda and Bogdan Enescu, who gave us their submitted paper (Toda and Enescu, 2011) before publication. We used the unified Japan Meteorology Agency (JMA) catalog with Hokkaido University, Hirosaki University, Tohoku University, Tokyo University, Nagoya University, Kyoto University, Kochi University, Kyushu University, Kagoshima University, Shizuoka Prefecture, Yokohama City, Tokyo Metropolis, JMA, Natural Research Institute for Earth Science and Disaster Prevention, National Institute of Advanced Industrial Science and Technology (AIST), Japan Agency for Marine-Earth Science and Technology (JAMSTEC), and Hot Springs Research Institute of Kanagawa Prefecture. We also used F-net focal mechanism solutions determined by NIED, the Generic Mapping Tools (Wessel and Smith, 1991) for drawing figures, the TSEIS visualization program package (Tsuruoka, 1997, 1998) for the study of hypocenter data, and the program by Okada (1992) for calculating the $\triangle \mathrm{CFF}$. We thank all of these organizations and individuals. This study is supported by the Special Project for Earthquake Disaster Mitigation in the Tokyo Metropolitan Area from the Ministry of Education, Culture, Sports, Science, and Technology of Japan.

\section{References}

Abe, K., Seismic displacement and ground motion near a fault: The Saitama Earthquake of September 21, 1931, J. Geophys. Res., 79(29), 4393-4399, 1974a.

Abe, K., Fault parameters determined by near- and far-field data: The Wakasa Bay earthquake of March 26, 1963, Bull. Seismol. Soc. Am., 64(5), 1369-1382, 1974b.

Aoi, S., B. Enescu, W. Suzuki, Y. Asano, K. Obara, T. Kunugi, and K. Shiomi, Stress transfer in the Tokai subduction zone from the 2009 Suruga Bay earthquake in Japan, Nature Geosci., 3, 496-500, doi:10.1038/ngeo885, 2010.

Chinnery, M. A., The deformation of the ground around surface faults, Bull. Seismol. Soc. Am., 51(3), 355-372, 1961.

Chinnery, M. A., The strength of the earth's crust under horizontal shear stress, J. Geophys. Res., 69(10), 2085-2089, 1964.

Cocco, M., S. Hainzl, F. Catalli, B. Enescu, A. M. Lombardi, and J. Woessner, Sensitivity study of forecasted aftershock seismicity based on Coulomb stress calculation and rate- and state-dependent frictional response, J. Geophys. Res., 115, B05307, doi:10.1029/2009JB006838, 2010.

Dietrich, J. H., A constructive law for rate of earthquake production and its application to earthquake clustering, J. Geophys. Res., 99(B2), 26012618, 1994.

Enescu, B. and K. Ito, Some premonitory phenomena of the 1995 Hyogo-ken Nanbu earthquake: seismicity, b-value and fractal dimension, Tectonophysics, 338(3-4), 297-314, 2001.

Eneva, M., R. E. Habermann, and M. W. Hamburger, Artificial and natural changes in the rates of seismic activity: a case study of the Garm Region, Tadjikistan (CIS), Geophys. J. Int., 116, 157-172, 1994.

Fukuyama, E., M. Ishida, D. S. Dreger, and H. Kawai, Automated seismic moment tensor determination by using on-line broadband seismic waveforms, Zisin 2, 51, 149-156, 1998 (in Japanese with English abstract).

Habermann, R. E., Precursory seismicity patterns: Stalking the mature seismic gap, in Earthquake Prediction Maurice Ewing Series IV, edited by D. W. Simpson and P. G. Richards, 29-42, AGU, Washington, D.C., 1981.

Habermann, R. E., Consistency of teleseismic reporting since 1963, Bull.
Seismol. Soc. Am., 72(1), 93-112, 1982a.

Habermann, R. E., Seismicity rates in the Kuriles Island Arc, 1973-1979, Earthq. Pred. Res., 1, 73-94, 1982b.

Habermann, R. E., Teleseismic detection in the Aleutian Island Arc, $J$. Geophys. Res., 88(B6), 5056-5064, 1983.

Habermann, R. E., Man-made changes of seismicity rates, Bull. Seismol. Soc. Am., 77(1), 141-159, 1987.

Habermann, R. E., Seismicity rate variations and systematic changes in magnitudes in teleseismic catalogs, Tectonophysics, 193, 277-289, 1991.

Habermann, R. E. and M. Wyss, Background seismicity rates and precursory seismic quiescence-Imperial Valley, California, Bull. Seismol. Soc. Am., 74(5), 1743-1755, 1984.

Hainzl, S. and Y. Ogata, Detecting fluid signals in seismicity data through statistical earthquake modeling, J. Geophys. Res., 110, B05S07, doi:10.1029/2004JB003247, 2005.

Hardebeck, J. L., J. J. Nazareth, and E. Hauksson, The static stress change triggering model: Constraints from two southern California aftershock sequences, J. Geophys. Res., 103(B10), 24427-24437, 1998.

Harris, R. A., Introduction to special section: stress triggers, stress shadows, and implications for seismic hazard, J. Geophys. Res., 103(B10), 24347-24358, 1998.

Harris, R. A. and R. W. Simpson, Changes in static stress on southern California faults after the 1992 Landers earthquake, Nature, 360, 251254, 1992.

Harris, R. A. and R. W. Simpson, In the shadow of 1857-the effect of the great Ft. Tejon earthquake on subsequent earthquakes in Southern California, Geophys. Res. Lett., 23(3), 229-232, 1996.

Harris, R. A., R. W. Simpson, and P. A. Reasenberg, Influence of static stress changes on earthquake locations in southern California, Nature, 375, 221-224, 1995.

Hashimoto, M., Static stress changes associated with the Kobe Earthquake: Calculation of changes in Coulomb Failure Function and comparison with seismicity change, Zisin 2, 48, 521-530, 1995 (in Japanese with English abstract).

Hashimoto, M., Correction to "Static stress changes associated with the Kobe Earthquake: Calculation of changes in Coulomb Failure Function and comparison with seismicity change", Zisin 2, 50, 21-27, 1997 (in Japanese with English abstract).

Helmstetter, A. and D. Sornette, Importance of direct and indirect triggered seismicity in the ETAS model of seismicity, Geophys. Res. Lett., 30(11), 1576, doi: 10.1029/2003GL017670, 2003.

Huang, Q. and T. Nagao, Seismic quiescence before the $2000 \mathrm{M}$ $=7.3$ Tottori earthquake, Geophys. Res. Lett., 29(12), 1578, doi: 10.1029/2001GL013835, 2002.

Huang, Q., G. A. Sobolev, and T. Nagao, Characteristics of the seismic quiescence and activation patterns before the $\mathrm{M}=7.2$ Kobe earthquake, January 17, 1995, Tectonophysics, 337, 99-116, 2001.

Imoto, M., Changes in seismicity of microearthquakes before major earthquakes in the Kanto area, Zisin 2, 45(2), 177-185, 1992 (in Japanese with English abstract).

Inouye, W., On the seismicity in the epicentral region and its neighborhood before the Niigata earthquake, Kenshin-jiho (Q. J. Seismol.), 29, 139144, 1965 (in Japanese with English abstract).

Ishibe, T., Spatial distribution of shallow crustal earthquakes and a source region of a large earthquake, Doctor Thesis, Department of Earth and Planetary Science, University of Tokyo, 120 pp, 2007.

Ishigaki, Y., Monitoring method for seismic activity in JapanDevelopment of a modified ETAS model through analysis of aftershock activities of M7.0, Kenshin-jiho (Q. J. Seismol.), 72(1-4), 1-25, 2009 (in Japanese with English abstract).

Japanese Network of Crustal Movement Observatories, Spatial distribution of strain-steps associated with the Earthquake of the Central Part of Gifu Prefecture, September 9, 1969, Bull. Earthq. Res. Inst., 48(6), 12171233, 1970 (in Japanese with English abstract).

Kanamori, H., Determination of effective tectonic stress associated with earthquake faulting, The Tottori earthquake of 1943, Phys. Earth Planet. Inter., 5, 426-434, 1972.

Kanamori, H., Mode of strain release associated with major earthquakes in Japan, Ann. Rev. Earth Planet. Sci., 1, 213-239, 1973.

Kasahara, K., The nature of seismic origins as inferred from seismological and geodetic observations, Bull. Earthq. Res. Inst., 35, 473-532, 1957.

Kasahara, K., The nature of seismic origins as inferred from seismological and geodetic observations, Bull. Earthq. Res. Inst., 36, 21-53, 1958.

Kasaya, T., N. Oshiman, N. Sumitomo, M. Uyeshima, Y. Ito, and D. Uehara, Resistivity structure around the hypocentral area of the 1984 
Western Nagano Prefecture earthquake in central Japan, Earth Planets Space, 54, 107-118, 2002.

Katsumata, K., Imaging the high b-value anomalies within the subducting Pacific plate in the Hokkaido corner, Earth Planets Space, 58, e49-e52, 2006.

Katsumata, K. and M. Kasahara, Precursory seismic quiescence before the 1994 Kuril Earthquake $(\mathrm{Mw}=8.3$ ) revealed by three independent seismic catalogs, Pure Appl. Geophys., 55, 443-470, 1999.

Katsumata, K. and M. Kasahara, Making a temporally homogeneous seismic catalog, Geophys. Bull. Hokkaido Univ., 67, 213-224, 2004 (in Japanese with English abstract).

Kawasaki, I., The focal process of the Kita-Mino earthquake of August 19, 1961, and its relationship to a Quaternary fault, Hatogayu-Koike fault, J. Phys. Earth, 23, 227-250, 1975.

Kelleher, J. and J. Savino, Distribution of seismicity before large strike slip and thrust-type earthquakes, J. Geophys. Res., 80(2), 260-271, 1975.

Kikuchi, M., EIC Seismological Note (No. 93s): Tottori-Ken Seibu earthquake (M7.3) of October, 6, 2000, http://www.eri.u-tokyo.ac.jp/ sanchu/Seismo_Note/EIC_News/001006.html, 2000.

Kikuchi, M., M. Nakamura, M. Yamada, M. Fushimi, Y. Tatsumi, and K. Yoshikawa, Source parameters of the 1948 Fukui Earthquake inferred from low-gain strong-motion records, Zisin 2, 52, 121-128, 1999 (in Japanese with English abstract).

King, G. C. P., R. S. Stein, and J. Lin, Static stress changes and the triggering of earthquake, Bull. Seismol. Soc. Am., 84(3), 935-953, 1994.

Kisslinger, C., An experiment in earthquake prediction and the 7th May 1986 Andreanof Islands Earthquake, Bull. Seismol. Soc Am., 78(1), 218-229, 1988.

Ma, K. F., C. H. Chan, and R. S. Stein, Response of seismicity to Coulomb stress triggers and shadows of the $1999 \mathrm{Mw}=7.6 \mathrm{Chi}-\mathrm{Chi}$, Taiwan, earthquake, J. Geophys. Res., 110(B5), doi:10.1029/2004JB003389, 2005.

Mikumo, T., Faulting mechanism of the Gifu earthquake of September 9, 1969, and some related problems, J. Phys. Earth, 21, 191-212, 1973.

Mikumo, K., H. Wada, S. Kaneshima, K. Imagawa, and M. Koizumi, Seismic activity in the northern Hida region before and after the 1984 western Nagano Prefecture earthquake, and the faulting mechanism of the main shock event, in Synthetic Investigation of Earthquake and Damage of the Western Nagano Prefecture Earthquake, 1984, pp 2133, Ministry of Education, Tokyo, 1985 (in Japanese).

Miyaoka, K. and A. Yoshida, Quiescence and precursory seismic activity before large interplate earthquakes along the Japan trench, Zisin 2, 45(4), 395-495, 1993 (in Japanese with English abstract).

Mogi, K., Some features of recent seismic activity in and near Japan (2) Activity before and after great earthquakes, Bull. Earthq. Res. Inst., 47, 395-417, 1969.

Mueller, K., S. E. Hough, and R. Bilham, Analysing the 1811-1812 New Madrid earthquakes with recent instrumentally recorded aftershocks, Nature, 429, 284-288, 2004.

Nakata, T., T. Kumamoto, Y. Kumahara, and Y. Yamanaka, "Morphometric Unit Model" of active faults for packaging faults into individual seismogenic faults, Active Fault Res., 24, 39-48, 2004 (in Japanese with English abstract).

Nanjo, K. Z., T. Ishibe, H. Tsuruoka, D. Schorlemmer, N. Hirata, and Y. Ishigaki, Analysis of the completeness magnitude and seismic network coverage of Japan, Bull. Seismol. Soc. Am., 100(6), 3261-3268, 2010.

Nanjo, K. Z., H. Tsuruoka, N. Hirata, and T. H. Jordan, Overview of the first earthquake forecast testing experiment in Japan, Earth Planets Space, 63, this issue, 159-169, 2011.

Obara, K., K. Kasahara, S. Hori, and Y. Okada, A densely distributed highsensitivity seismograph network in Japan: Hi-net by National Research Institute for Earth Science and Disaster Prevention, Rev. Sci. Instrum., 76, 021301, 2005.

Odaka, S. and K. Maeda, Changes in seismic activities in the focal region and nearby seismic nests before the 1987 Chiba-toho-oki earthquake, Zisin 2, 47, 365-374, 1994 (in Japanese with English abstract).

Ogata, Y., Monitoring of anomaly in the aftershock sequence of the 2005 earthquake of M7.0 off coast of the western Fukuoka, Japan, by the ETAS model, Geophys. Res. Lett., 33, L01303, doi:10. 1029/2005GL024405, 2006.

Ogata, Y., Seismicity and geodetic anomalies in a wide area preceding the Niigata-Ken-Chuetsu earthquake of 23 October 2004, central Japan, $J$. Geophys. Res., 112, B10301, doi:10.1029/2006JB004697, 2007.

Ogata, Y. and S. Toda, Bridging great earthquake doublets through silent slip: On- and off-fault aftershocks of the 2006 Kuril Island subduction earthquake toggled by a slow slip on the outer rise normal fault the 2007 great earthquake, J. Geophys. Res., 115, B06318, doi:10.
1029/2009JB006777, 2010.

Ohtake, M., T. Matsumoto, and G. V. Latham, Seismicity gap near Oaxaca, southern Mexico as a probable precursor to a large earthquake, Pure Appl. Geophys., 115, 375-385, 1977.

Okada, Y., Internal deformation due to shear and tensile faults in a half space, Bull. Seismol. Soc. Am., 82(2), 1018-1040, 1992.

Okada, Y., K. Kasahara, S. Hori, K. Obara, S. Sekiguchi, H. Fujiwara, and A. Yamamoto, Recent progress of seismic observation networks in Japan-Hi-net, F-net, K-NET and KiK-net—, Earth Planets Space, 56, Xv-xxviii, 2004.

Omori, F., On after-shocks of earthquakes, J. Fact. Sci. Univ. Tokyo, 7, $111-120,1894$

Perez, O. J. and C. H. Scholtz, Heterogeneities of the instrumental seismicity catalog (1904-1980) for strong shallow earthquakes, Bull. Seismol. Soc. Am., 74(2), 669-686, 1984.

Reasenberg, P. A., Second-order moment of Central California seismicity, 1969-1982, J. Geophys. Res., 90(B7), 5479-5495, 1985.

Reasenberg, P. A. and R. W. Simpson, Response of regional seismicity to the static stress change produced by the Loma Prieta earthquake, Science, 255, 1687-1690, 1992.

Sagiya, T., S. Miyazaki, and T. Tada, Continuous GPS array and presentday crustal deformation of Japan, Pure Appl. Geophys., 157, 23032322, 2000.

Sato, H., A study of horizontal movement of the earth crust associated with destructive earthquakes in Japan, Bull. Geogr. Surv. Inst., 19, 89-130, 1973.

Schorlemmer, D., N. Hirata, F. Euchner, Y. Ishigaki, and H. Tsuruoka, A probabilistic completeness study in Japan, The 7th General Assembly of Asian Seismological Commission and Seismological Society of Japan, 2008 Fall Meeting, Program and abstract, Y3-214, Tsukuba, Japan, 24 27 November, 2008, 2008.

Simpson, R. W. and P. A. Reasenberg, Earthquake-induced static-stress changes on central California faults, in The Loma Prieta, California, Earthquake of October 17, 1989-Tectonic Processes and Models, U.S. Geol. Surv. Prof. Pap., 1550-F, 55-89, 1994.

Steacy, S., J. Gomberg, and M. Cocco, Introduction to special section: Stress transfer, earthquake triggering, and time-dependent seismic hazard, J. Geophys. Res., 110, B05S01, doi:10.1029/2005JB003692, 2005.

Stein, R. S., The role of stress transfer in earthquake occurrence, Nature, 402, 605-609, 1999.

Stein, R. S., G. C. P. King, and J. Lin, Change in Failure Stress on the Southern San Andreas fault system caused by the 1992 magnitude $=7.4$ Landers Earthquake, Science, 258, 1328-1332, 1992.

Stein, R. S., G. C. P. King, and J. Lin, Stress triggering of the 1994 Mw $=6.7$ Northridge, California, Earthquake by its predecessors, Science, 265, 1432-1435, 1994.

Stein, S. and M. Liu, Long aftershock sequences within continents and implications for earthquake hazard assessment, Nature, 462, 87-89, 2009.

Takanami, T., I. S. Sacks, J. A. Snoke, Y. Motoya, and M. Ichiyanagi, Seismic quiescence before the Hokkaido-Toho-Oki earthquake of October 4, 1994, J. Phys. Earth, 44, 193-203, 1996.

Taylor, D. W. A., J. A. Snoke, I. S. Sacks, and T. Takanami, Seismic quiescence before the Urakawa-Oki earthquake, Bull. Seismol. Soc. Am., 81(4), 1255-1271, 1991.

Toda, S., Coulomb stresses imparted by the 25 March $2007 \mathrm{Mw}=6.6$ NotoHanto, Japan, earthquake explain its 'butterfly' distribution of aftershocks and suggest a heightened seismic hazard, Earth Planets Space, 60, 1041-1046, 2008.

Toda, S. and B. Enescu, Rate/state Coulomb stress transfer model for the CSEP Japan seismicity forecast, Earth Planets Space, 63, this issue, 171-185, 2011.

Toda, S. and S. Matsumura, Spatio-temporal stress states estimated from seismicity rate changes in the Tokai region, central Japan, Tectonophysics, 417, 53-68, 2006.

Toda, S., R. S. Stein, P. A. Reasenberg, and J. H. Dieterich, Stress transferred by the $\mathrm{Mw}=6.8$ Kobe, Japan, shock: Effect on aftershocks and future earthquake probabilities, J. Geophys. Res., 103(B10), 2454324565, 1998.

Toda, S., R. S. Stein, and T. Sagiya, Evidence from the AD 2000 Izu islands earthquake swarm that stressing rate governs seismicity, Nature, 419, 58-61, 2002.

Tsuruoka, H., Development of seismicity analysis system on WWW (2), Programme and Abstracts, The Seismological Society of Japan, P04, 1997.

Tsuruoka, H., Development of seismicity analysis software on worksta- 
tion, Tech. Res. Rep. ERI, Univ. Tokyo, 2, 34-42, 1998.

Tsuruoka, H., N. Hirata, D. Schorlemmer, F. Euchner, K. Z. Nanjo, and T. H. Jordan, CSEP Testing Center and the first results of the earthquake forecast testing experiment in Japan, Earth Planets Space, 2011 (submitted).

Utsu, T., Statistical study on the occurrence of aftershocks, Geophys. Mag., 30, 521-605, 1961.

Utsu, T., Seismic activity in Hokkaido and its vicinity, Geophys. Bull. Hokkaido Univ., 20, 51-75, 1968 (in Japanese with English abstract).

Utsu, T., Seismicity of Japan from 1885 through 1925: A new catalog of earthquakes of $M=6$ Felt in Japan and smaller earthquakes which caused damage in Japan, Bull. Earthq. Res. Inst., 54(2), 253-308, 1979 (in Japanese with English abstract).

Utsu, T., Y. Ogata, and R. S. Matsu'ura, The century of the Omori formula for a decay law of aftershock activity, J. Phys. Earth, 43, 1-33, 1995.

Wessel, P. and W. H. F. Smith, Free software helps map and display data, Eos Trans. AGU, 72, 441, 1991.

Wiemer, S. and M. Wyss, Seismic quiescence before the Landers (M=7.5) and Big Bear (M=6.5) 1992 Earthquakes, Bull. Seismol. Soc. Am., 84(3),
900-916, 1994.

Wyss, M., Seismic quiescence precursor to the 1983 Kaoiki $(\mathrm{Ms}=6.6)$, Hawaii, earthquake, Bull. Seismol. Soc. Am., 76(3), 785-800, 1986.

Wyss, M. and R. O. Burford, Current episodes of seismic quiescence along the San Andreas fault between San Juan Bautista and Stone Canyon, California: Possible precursors to local moderate mainshocks?, U.S. Geol. Surv., Open-File Rep., 85-745, 367-426, 1985.

Yamasaki, N. and F. Tada, The Oku-Tango Earthquake of 1927, Bull. Earthq. Res. Inst., 4, 159-157, 1928.

Yamashina, K. and T. Tada, A fault model of the 1984 Western Nagano Prefecture Earthquake based on the distance change of trilateration points, Bull. Earthq. Res. Inst., 60, 221-230, 1985 (in Japanese with English abstract).

Zhuang, J., Y. Ogata, and D. Vere-Jones, Stochastic declustering of spacetime earthquake occurrences, J. Am. Stat. Ass., 97, 369-380, 2002.

T. Ishibe (e-mail: ishibe@eri.u-tokyo.ac.jp), K. Shimazaki, H. Tsuruoka, Y. Yamanaka, and K. Satake 